\title{
Microbiological and Toxicological Assessment of Pharmaceutical Wastewater from the Lagos Megacity, Nigeria
}

\author{
Avemaria Ifeoma Obasi, ${ }^{1}$ Nnamdi Henry Amaeze, ${ }^{2}$ and Damilola Dorcas Osoko ${ }^{2}$ \\ ${ }^{1}$ Department of Microbiology, University of Lagos, Akoka-Yaba, Lagos, Nigeria \\ ${ }^{2}$ Ecotoxicology Laboratory, Department of Zoology, University of Lagos, Akoka-Yaba, Lagos, Nigeria \\ Correspondence should be addressed to Nnamdi Henry Amaeze; amaezenh@gmail.com
}

Received 23 May 2014; Revised 31 August 2014; Accepted 31 August 2014; Published 28 September 2014

Academic Editor: Qiusheng Zheng

Copyright (C) 2014 Avemaria Ifeoma Obasi et al. This is an open access article distributed under the Creative Commons Attribution License, which permits unrestricted use, distribution, and reproduction in any medium, provided the original work is properly cited.

\begin{abstract}
We conducted a microbiological and toxicological profiling of a pharmaceutical wastewater, one of the major wastes entering the Lagos lagoon. The morphological characterization of seven bacterial isolates from the wastewater indicated that 4 of them were gram positive bacilli while 3 were cocci of both gram reactions. The bacterial isolates exhibited varying degrees of enzyme activities but most were able to hydrolyze starch to yield amylase. Only 3 of the isolates showed prospects as antibacterial agents, given their moderate inhibition to Staphylococcus xylosus relative to 8 other species tested. Overall, $81.3 \%$ of the isolates were resistant, and $3.3 \%$ were susceptible while $15.4 \%$ of the isolates showed intermediate sensitivity to the antibiotics. The assessment of antioxidant activities in liver samples of Nile tilapia, Oreochromis niloticus, exposed to sublethal concentrations of the effluents indicated some form of oxidative stress given the higher levels of lipid peroxidation product, malondialdehyde, in the exposed fishes relative to the control kept in dechlorinate tap water. But for reduced glutathione, activities of the antioxidative stress enzymes, superoxide dismutase (SOD), catalase (CAT), and glutathione-s-transferase (GST), were higher in the effluent exposed tilapia. Responses were not dose dependent and enzyme activities were often higher at day 14 compared to day 28 . This relevance of the findings to water quality was discussed.
\end{abstract}

\section{Introduction}

The fate of pharmaceutical effluents in aquatic environments is increasingly eliciting scientific inquiry owing to recent findings of their effects in biological systems [1]. Nigeria has a few pharmaceutical companies most of which are situated in Ogun and Lagos States in the country's south western region, discharging effluents into neighbouring rivers, creeks, and lagoons. Pharmaceutical effluents are wastes generated by pharmaceutical industries during the process of drug manufacturing [2]. These wastes by virtue of their source are composed of a variety of biologically active chemical components including antibiotics, lipid regulators, antiinflammatories, antiepileptics, tranquilizers, oil and grease [3], heavy metals [4], and myriads of other compounds depending on the drug or personal care products being manufactured. Pharmaceutical effluents particularly those rich in contraceptives have also been linked with endocrine disrupting effects [5]. Microbial actions on effluents often result in products which may also interfere with endocrine functions. Mycobacterium smegmatis is known to metabolize stigmasterol in effluents into a potent androgen, androstenedione [6]. Exposure of aquatic organisms to androgenic or estrogenic compounds in pharmaceutical wastes and sewage is a known cause of sex reversal in fishes which could impair reproductive success [7].

Industrial wastewater management systems in Nigeria are either nonexistent, inappropriate, or at best inefficient. When efforts are made towards effluent management, basic dilution, filtration, sedimentation, and aeration techniques are usually put in place and these may not have the capacity to break down the chemical components of the effluents. These effluents eventually end up in natural water bodies where they cause contamination of water and toxic effects on the biotic communities [8]. Effluents typically contain various components, some of which could have the tendency to 
combine with the unsaturated fatty acids of the phospholipids of cell membranes leading to oxidative damage and release of byproducts such as malondialdehyde [9]. The resulting oxidative damage and the reactive oxygen species are continually countered by the action of antioxidative stress enzymes such as superoxide dismutase (SOD), catalase (CAT), and glutathione-s-transferase (GST) [9].

In view of the fate of pharmaceuticals in our environment and the growing concerns over their biological effects, we therefore conducted an extensive microbiological profiling and toxicological evaluations using the Nile tilapia, Oreochromis niloticus (a commonly bred fish for laboratory studies in Nigeria), of pharmaceutical wastewater from an industrial estate in the South-West of Nigeria. The term wastewater is used in this study to represent effluents which have not yet been discharged into the environment.

\section{Materials and Methods}

2.1. Sample Collection. Wastewater was sampled from the reservoir of a pharmaceutical company in industrial estate, at Agbara, the South-West of Nigeria. Untreated wastewater sample from the production of ciprofloxacin was collected directly into a 4-liter sterile plastic container and put on ice and immediately taken to the laboratory for routine microbiological, toxicological, and biochemical analyses. Storage was at $4^{\circ} \mathrm{C}$ prior to analysis and assays.

2.2. Assessment of the Physicochemical Characteristics of the Effluents. The wastewater sample was analyzed for basic physicochemical characteristics using standard methods as described by APHA-AWWA-WEF [10]. The parameters analysed in the effluent sample included $\mathrm{pH}$, salinity, conductivity, total dissolved solids (TDS), dissolved oxygen (DO), biological oxygen demand (BOD), chemical oxygen demand $(\mathrm{COD})$, iron $(\mathrm{Fe})$, zinc $(\mathrm{Zn})$, copper $(\mathrm{Cu})$, nickel $(\mathrm{Ni})$, and cadmium (Cd). Specifically, the heavy metal concentrations were measured using atomic absorption spectrophotometer, after the samples have been subjected to acid digestion. Determination of DO level was not possible in situ; thus, samples were stored cool $\left(4^{\circ} \mathrm{C}\right)$ at the point of collection and transported to the lab for immediate analysis, while other analyses were carried out within 1 week of sampling. Also all glassware was subjected to heat and acid wash before use to prevent contamination and false readings.

2.3. Determination of THC. The analysis for total hydrocarbon content (THC) of the sample was done using ASTM D 2887-93 method [11] on an Agilent 4890D gas chromatograph/flame ionization detector subjected to prior calibration using a known standard (Sigma Aldrich, USA).

\subsection{Microbiological Analysis}

2.4.1. Isolation of Microorganism. One $\mathrm{mL}$ of water sample was added to $9 \mathrm{~mL}$ of sterile distilled water and a tenfold serial dilution was done, and the lower, middle, and high dilutions were plated in duplicate into nutrient agar (Biotec; UK),
MacConkey agar, and potato dextrose agar plates already prepared. These were incubated at $37^{\circ} \mathrm{C}$ for $18-24 \mathrm{hrs}$ for total bacteria and coliforms. Also, incubation for 3 to 5 days at $27^{\circ} \mathrm{C}$ (Rm temp.) was achieved for fungi isolates. Colonies on plates were observed and counted and the population density was estimated; bacterial colonies were picked according to their cultural morphology on the plates and these were streaked on new nutrient agar plates for pure colonies [12].

2.4.2. Morphological and Enzymatic Assay of Bacterial Isolates. The morphological characteristics of isolates were observed and recorded and this was the basis for the isolation of colonies. The cell shape and arrangements of isolates were determined following the standard procedures of basic stain, gram stain [12]. The isolates were screened for the presence of protease, amylase, and phospholipase using methods as described by Talaro [13].

2.4.3. Screening for Antibacterial Agent. All isolates were screened for antibacterial activity against 8 types of clinical bacterial species, obtained from Lagos University Teaching Hospital (LUTH), using the agar well diffusion method as described by John et al. [14]. Overnight bacterial cultures in nutrient broth were standardized and adjusted to a McFarland standard of 0.5 which is equivalent to approximately $10^{8} \mathrm{cfu} / \mathrm{mL}$. The already prepared Mueller Hinton agar plates were swabbed with the different clinical bacterial isolates with a sterile swab stick; this was done by streaking the swab over the entire surface of the Mueller Hinton agar plates and the plates were rotated $60^{\circ}$ and the streaking was repeated until the entire plate was swabbed. Complete inoculation was done by running the swab around the rim of the agar plates. The lid of the plates was left open for about 5 minutes to allow any excess moisture to be absorbed before boring the agar with a sterile cork borer. Few drops of about $0.1 \mathrm{~mL}$ of the test bacterial isolate were introduced using a $100 \mu \mathrm{L}$ micropipette into the wells and this was repeated for all the swabbed clinical bacterial isolates. The clinical bacteria used are four gram positive bacteria (Staphylococcus xylosus, Staphylococcus warneri, Staphylococcus epidermidis, and Enterococcus faecalis) and four gram-negative bacteria (Pseudomonas aeruginosa, Proteus mirabilis, Shigella sp., and Salmonella sp.). The plates were incubated at $37^{\circ} \mathrm{C}$ for $24 \mathrm{hrs}$. The assay for antimicrobial properties was determined by measuring the diameter of the inhibition zone around the wells and interpretation of results was expressed as moderate ( 6 to $9 \mathrm{~mm}$ ), strong (10 to $14 \mathrm{~mm}$ ), or very strong (15 to $18 \mathrm{~mm}$ ) according to Liasi et al. [15].

\subsection{Determination of the Acute Toxicity of the Effluent}

2.5.1. Selection and Acclimatization of Test Fishes. The Nile tilapia Oreochromis niloticus fingerlings, measuring an average of $1.55 \pm 0.15 \mathrm{~cm}$, were obtained from a commercial fish farm in Badagry on the outskirts of Lagos. The fishes were transported in aerated plastic tanks and acclimatized for 1 week in dark plastic tanks (stocking density: 10 fishes per litre, photoperiod: $12 \mathrm{hrs}$ dark $12 \mathrm{hrs}$ light). The fish stock selected 
for the assay recorded mortality of less than $1 \%$ after 1 week of acclimatization in the laboratory.

2.5.2. Bioassay Procedure. Wastewater samples were removed from storage in the fridge $\left(4^{\circ} \mathrm{C}\right)$ and allowed to adjust to room temperature, until the temperature of the samples was approximately equal to those of the water in the bioassay tanks (about $26^{\circ} \mathrm{C}$ ). The bioassay tanks had a stocking density of 10 fingerlings per litre and concentrations were set in duplicate, with each bioassay repeated twice after an initial range finding experiment.

Quantal response of mortality was employed in assessing effluent toxicity based on established techniques [16] and the 96-hour $\mathrm{LC}_{50}$ of the effluent samples acting against the tilapia fingerlings was used in determining the sublethal concentrations for the biochemical assays.

2.6. Assessment of Biochemical Responses of O. niloticus Exposed to the Pharmaceutical Effluent. After 14 and 28 days of exposure of the fingerlings to sublethal concentrations of the pharmaceutical effluent (1/10th 96-hour $\mathrm{LC}_{50}=$ $5.120 \mathrm{~mL} / \mathrm{L} ; 1 / 100$ th 96 -hour $\mathrm{LC}_{50}=0.512 \mathrm{~mL} / \mathrm{L}$ ), their liver samples were excised using a sterile dissecting set after a sharp blow to their head to immobilize them. (Ethical permit was in line with the Zoology Department, University of Lagos standard for fair treatment of lab animals.)

The liver samples were collected in unused universal bottles prior to analysis. The samples were assessed for the lipid peroxidation product, malondialdehyde (MDA), using the thiobarbituric acid reaction (TBARS) assay as described by Yagi [17]. Also antioxidative stress enzyme activities were assessed using established techniques as follows: superoxide dismutase [18], catalase [19], reduced glutathione as nonprotein sulfhydryls [20], and glutathione-s-transferase based on their relatively high activity with 1-chloro-2,4-dinitrobenzene as a second substrate [21].

2.7. Statistical Analysis. The Probit assay was used to determine the dose-response of mortality using independent sample $t$-test and two-way ANOVA (SPSS Version 16). The software used was SPSS Version 16 to determine the 96-hour $\mathrm{LC}_{50}$ (i.e., the median lethal concentration that causes $50 \%$ mortality of the exposed fingerlings).

\section{Results}

3.1. Physicochemical Characteristics of the Pharmaceutical Effluent. The physicochemical characteristics of the pharmaceutical effluents showed that it was slightly acidic, with some considerable levels of electrical conductivity. There was also low level of dissolved oxygen and evidence of degradation action of microorganisms with BOD and COD levels of 36.0 and $72.0 \mathrm{mg} / \mathrm{L}$, respectively. The effluent was low on heavy metals except for iron and manganese which were high in concentrations (Table 1).

3.2. Microbiological Assessments of the Pharmaceutical Effluent. The initial characterization of the microbial population
TABLE 1: Physicochemical characteristics of the pharmaceutical effluents.

\begin{tabular}{|c|c|c|}
\hline \multicolumn{2}{|l|}{ Parameter } & \multirow{2}{*}{$\begin{array}{c}\text { Effluent } \\
30\end{array}$} \\
\hline Color & PtCo & \\
\hline Turbidity & FAU & 16 \\
\hline \multicolumn{2}{|l|}{$\mathrm{pH}$} & 5.0 \\
\hline \multicolumn{2}{|c|}{ Dissolved oxygen (mg/L) } & 4.70 \\
\hline \multicolumn{2}{|c|}{ Biological oxygen demand $(\mathrm{mg} / \mathrm{L})$} & 36.0 \\
\hline \multicolumn{2}{|c|}{ Chemical oxygen demand $(\mathrm{mg} / \mathrm{L})$} & 72.0 \\
\hline \multicolumn{2}{|c|}{ Conductivity $(\mu \mathrm{S} / \mathrm{cm})$} & 320 \\
\hline \multicolumn{2}{|c|}{ Total dissolved solids (mg/L) } & 160 \\
\hline \multicolumn{2}{|c|}{ Salinity (\%o) } & 0 \\
\hline \multicolumn{2}{|c|}{ Temperature $\left({ }^{\circ} \mathrm{C}\right)$} & 26.65 \\
\hline \multicolumn{2}{|c|}{ Chloride (mg/L) } & 66 \\
\hline \multicolumn{2}{|c|}{ Sulfate (mg/L) } & 5.0 \\
\hline \multicolumn{2}{|c|}{ Total hardness (mg/L) } & 180 \\
\hline \multicolumn{2}{|c|}{ Calcium (mg/L) } & 120 \\
\hline \multicolumn{2}{|c|}{ Magnesium (mg/L) } & 60 \\
\hline \multicolumn{2}{|c|}{ Sodium (mg/L) } & 11.50 \\
\hline \multicolumn{2}{|c|}{ Oil and grease $(\mathrm{mg} / \mathrm{L})$} & 0.10 \\
\hline \multicolumn{2}{|c|}{ Total carbonate alkalinity $(\mathrm{mg} / \mathrm{L})$} & 0 \\
\hline \multicolumn{2}{|c|}{ Nitrate $(\mathrm{mg} / \mathrm{L})$} & 0.18 \\
\hline \multicolumn{2}{|c|}{ Nitrite (mg/L) } & 0.01 \\
\hline \multicolumn{2}{|c|}{ Phosphate (mg/L) } & 1.96 \\
\hline \multicolumn{2}{|c|}{ Hydrogen sulfide (mg/L) } & 0 \\
\hline \multicolumn{2}{|l|}{ TOC (\%) } & 4.40 \\
\hline \multicolumn{2}{|c|}{ Iron $(\mathrm{mg} / \mathrm{L})$} & 36.45 \\
\hline \multicolumn{2}{|c|}{ Manganese $(\mathrm{mg} / \mathrm{L})$} & 20.0 \\
\hline \multicolumn{2}{|c|}{ Copper (mg/L) } & 0.82 \\
\hline \multicolumn{2}{|c|}{ Zinc (mg/L) } & 0.88 \\
\hline \multicolumn{2}{|c|}{ Lead (mg/L) } & 0.22 \\
\hline \multicolumn{2}{|c|}{ Nickel (mg/L) } & 0.26 \\
\hline \multicolumn{2}{|c|}{ Chromium (mg/L) } & 0.31 \\
\hline Mercury ( & & $\mathrm{ND}$ \\
\hline Arsenic ( & & 0.04 \\
\hline Barium (n & & 0.88 \\
\hline Cobalt (m & & 0.04 \\
\hline
\end{tabular}

ND: not detected.

densities from the effluent indicated a bacterial and total fungal count of $2.7 \times 10^{12} \mathrm{cfu} / \mathrm{mL}$ and $4.8 \times 10^{4} \mathrm{cfu} / \mathrm{mL}$, respectively. There was no evidence of coliform growth when samples were cultured on MacConkey agar, thus implying that there was no faecal contamination in the effluent.

3.2.1. Morphological Characteristics of Isolates. An assessment of the cultural characteristics of the isolates observed on plates indicated that the seven isolates were mostly circular in form except for isolate ME6 (Table 2). The isolates were all opaque and smooth, with two of them being gram negative while the other four were gram positive. Also, cellular morphology showed that four of the isolates are rods while three are cocci. All but one of the cocci were gram negative, 
TABLE 2: Morphology of bacterial isolates from pharmaceutical wastewater.

\begin{tabular}{|c|c|c|c|c|c|c|c|}
\hline Isolates & ME1 & ME2 & ME3 & ME4 & ME5 & ME6 & ME7 \\
\hline Form of colony & Circular & Circular & Circular & Circular & Circular & Punctiform & Circular \\
\hline Translucency/opacity & Opaque & Opaque & Opaque & Opaque & Opaque & Opaque & Opaque \\
\hline Elevation of colony & Flat & Flat & Flat & Flat & Flat & Raised & Flat \\
\hline Margin of colony & Entire & Entire & Entire & Entire & Entire & Undulate & Entire \\
\hline Surface of colony & Smooth & Smooth & Smooth & Smooth & Smooth & Smooth & Smooth \\
\hline Cell morphology & Cocci & Rods & Cocci & Rods & Cocci & Rods & Rods \\
\hline Gram stain reaction & Negative & Positive & Positive & Positive & Negative & Positive & Positive \\
\hline Pigmentation & Light yellow & Milky white & Yellow & Milky white & Milky white & Milky white & Yellow \\
\hline
\end{tabular}

while all the rods were gram positive and the pigmentation of isolates ranged from milky white to yellow (Table 2).

3.2.2. Assessment of Enzymatic Assay of Bacterial Isolates. Four isolates (ME2, ME4, ME5, and ME7) were observed to hydrolyze starch, producing amylase, of which two ME4 and ME5 produced high amylase activity. The only bacterial isolates that possessed moderate protease activity and high phospholipase activity were ME4 and ME7, respectively, (Table 3).

\subsubsection{Inhibitory Spectrum of Antibacterial-Producing Bacteria} on Clinical Isolates. The isolates were tested for their ability to produce inhibitory substances against 8 indicator species (Table 4). Isolates ME2, ME3, and ME7 amongst others showed moderate inhibition zones of $3 \mathrm{~mm}, 6 \mathrm{~mm}$, and $8 \mathrm{~mm}$, respectively, against gram positive Staphylococcus $x y$ losus.

3.2.4. Antibiotic Susceptibility Pattern of Bacterial Isolates. Susceptibility test of the isolates using the Kirby-Bauer method as shown in Table 5 indicated that bacterial isolates ME3, ME5, and ME6 were resistant to all 13 antibiotics tested, although other isolates revealed some level of resistance to some of the antibiotics as well. The pattern of susceptibility is as shown in Figure 1. Overall, $81.3 \%$ of the isolates were resistant, and $3.3 \%$ of the isolates were susceptible while $15.4 \%$ showed intermediate sensitivity to the antibiotics (Figure 2).

3.2.5. Acute Toxicity of the Pharmaceutical Effluents on Oreochromis niloticus. The results of the acute toxicity studies on O. niloticus indicate a generally low to moderate toxicity. On the basis of derived 96-hour $\mathrm{LC}_{50}$ values, the wastewater was found to have $\mathrm{LC}_{50}$ value of $51.20 \mathrm{~mL} / \mathrm{L}$ (Table 6).

Biochemical responses products in Oreochromis niloticus were exposed to sublethal concentrations of pharmaceutical wastewater.

3.2.6. Lipid Peroxidation. The aldehyde byproduct of lipid peroxidation, MDA, was lower in the control at both days 14 and 28 relative to the wastewater exposed tilapia groups (Figure 3). Specifically, the MDA levels at day 14 were significantly lower $(P<0.05)$ in the control group than those exposed to the wastewater. However, by day 28 of the experiments, the levels, though lower in the controls,
TABLE 3: Enzymatic assay of bacterial isolates from pharmaceutical wastewater.

\begin{tabular}{lccc}
\hline Isolates/enzyme & Amylase & Protease & Phospholipase \\
\hline ME1 & ND & ND & ND \\
ME2 & $7++$ & ND & ND \\
ME3 & ND & ND & ND \\
ME4 & $11+++$ & $8++$ & ND \\
ME5 & $(14)+++$ & ND & ND \\
ME6 & ND & ND & ND \\
ME7 & $6+$ & ND & +++ \\
\hline
\end{tabular}

Degree of enzymatic activity: $+=$ low $(\leq 2 \mathrm{~mm}),++=$ moderate $(>2-8 \mathrm{~mm})$, $+++=$ high $(>8 \mathrm{~mm})$, and $\mathrm{ND}=$ nondetectable.

did not vary significantly with those in the effluent exposed groups. Among the exposed groups, MDA was higher in those exposed to $1 / 100$ th 96 hrs $\operatorname{LC}_{50}(P>0.05)$ at day 14 but the reverse was the case by day 28 , with those exposed to the $1 / 10$ th 96 hrs LC $_{50}$ having a significantly higher level $(P<0.05)$ of MDA (Figure 3$)$.

3.2.7. Superoxide Dismutase. The activities of SOD in the liver samples from the exposed $O$. niloticus were observed to reduce significantly $(P<0.05)$, between the 14th and 28th days of assessments except in the control samples. The least as well as the highest SOD activities in the tilapia fingerlings were recorded at days 14 and 28, respectively, in the control individuals (Figure 4). Also, SOD activity was lower in those exposed to $1 / 10$ th $96 \mathrm{hrs} \mathrm{LC}_{50}$ at both days 14 and 28 of exposure but the difference was not significant $(P>0.05)$.

3.2.8. Catalase. Catalase enzyme activity was least at day 14 in control tilapia fingerlings and its levels were significantly lower $(P<0.05)$ than in those exposed to $1 / 10$ th and $1 / 100$ th of the $\mathrm{LC}_{50}(P<0.05)$. Among the wastewater exposed group, 1/10th 96 hrs LC $_{50}$ concentration induced higher activity at day 14 but the reverse was the case by day 28 (Figure 5).

3.2.9. Reduced Glutathione. The extent of glutathione reduction (GSH) was highest in the control fingerlings at day 14 and least in those exposed to $1 / 10$ th 96 hrs LC $_{50}$ concentrations. The reverse was the case by day 28 with those exposed to $1 / 10$ th $96 \mathrm{hrs} \mathrm{LC}_{50}$ having the highest GSH levels while 
TABLE 4: Inhibitory spectrum of bacterial isolates from pharmaceutical wastewater.

\begin{tabular}{|c|c|c|c|c|c|c|c|}
\hline Indicator species/isolate & ME1 & ME2 & ME3 & ME4 & ME5 & ME6 & ME7 \\
\hline \multicolumn{8}{|l|}{ Gram positive } \\
\hline S. epidermidis & ND & ND & ND & ND & ND & ND & ND \\
\hline S. warneri & ND & ND & ND & ND & ND & ND & ND \\
\hline S. xylosus & ND & $3+$ & $6+$ & ND & $\mathrm{ND}$ & ND & $8+$ \\
\hline E. faecalis & ND & ND & ND & ND & $\mathrm{ND}$ & ND & ND \\
\hline \multicolumn{8}{|l|}{ Gram negative } \\
\hline P. aeruginosa & ND & ND & ND & ND & ND & ND & ND \\
\hline P. mirabilis & ND & ND & ND & ND & $\mathrm{ND}$ & ND & $\mathrm{ND}$ \\
\hline Salmonella spp. & ND & ND & ND & ND & ND & ND & ND \\
\hline Shigella spp. & ND & $\mathrm{ND}$ & ND & $\mathrm{ND}$ & $\mathrm{ND}$ & $\mathrm{ND}$ & ND \\
\hline
\end{tabular}

Degree of inhibition: + = moderate inhibition zone (6 to $9 \mathrm{~mm}),++=$ strong inhibition zone (10 to $14 \mathrm{~mm})$, +++ = very strong inhibition zone (15 to $18 \mathrm{~mm}$ ), and $\mathrm{ND}=$ nondetectable.

TABLE 5: Susceptibility pattern of bacterial isolates from pharmaceutical wastewater.

\begin{tabular}{|c|c|c|c|c|c|c|c|}
\hline Antibiotics/isolates & ME1 & ME2 & ME3 & ME4 & ME5 & ME6 & ME7 \\
\hline AMP10 & $\mathrm{R}$ & $\mathrm{R}$ & $\mathrm{R}$ & $\mathrm{R}$ & $\mathrm{R}$ & $\mathrm{R}$ & $\mathrm{R}$ \\
\hline CAZ30 & $\mathrm{R}$ & $\mathrm{R}(8)+++$ & $\mathrm{R}$ & $\mathrm{R}$ & $\mathrm{R}$ & $\mathrm{R}$ & $\mathrm{R}$ \\
\hline CRX30 & $\mathrm{R}$ & $\mathrm{R}(15)+++$ & $\mathrm{R}$ & $\mathrm{R}$ & $\mathrm{R}$ & $\mathrm{R}$ & $\mathrm{R}$ \\
\hline GEN10 & $(20)++$ & $(16)++$ & $\mathrm{R}$ & $\mathrm{R}(15)+++$ & $\mathrm{R}(14)+++$ & $\mathrm{R}$ & $(17)++$ \\
\hline CPR5 & $(20)++$ & $(20)++$ & $\mathrm{R}$ & $(20)++$ & $\mathrm{R}$ & $\mathrm{R}$ & $(20)++$ \\
\hline OFL5 & $(18)++$ & $(16)++$ & $\mathrm{R}$ & $(22)+$ & $\mathrm{R}(10)+++$ & $\mathrm{R}$ & $\mathrm{R}(15)+++$ \\
\hline AUG30 & $\mathrm{R}$ & $\mathrm{R}$ & $\mathrm{R}$ & $\mathrm{R}$ & $\mathrm{R}$ & $\mathrm{R}$ & $\mathrm{R}$ \\
\hline NIT300 & $\mathrm{R}(11)+++$ & $(18)++$ & $\mathrm{R}$ & $(24)+$ & $\mathrm{R}(12)+++$ & $\mathrm{R}$ & $(20)++$ \\
\hline E15 & $(20)++$ & $\mathrm{R}(8)+++$ & $\mathrm{R}(12)+++$ & $(20)++$ & $\mathrm{R}$ & $\mathrm{R}$ & $\mathrm{R}(12)+++$ \\
\hline DA2 & $\mathrm{R}$ & $\mathrm{R}$ & $\mathrm{R}$ & $\mathrm{R}(15)+++$ & $\mathrm{R}$ & $\mathrm{R}$ & $\mathrm{R}$ \\
\hline NA30 & $(22)+$ & $\mathrm{R}$ & $\mathrm{R}(15)+++$ & $\mathrm{R}(14)+++$ & $\mathrm{R}$ & $\mathrm{R}(12)+++$ & $\mathrm{R}(15)+++$ \\
\hline $\mathrm{C} 30$ & $\mathrm{R}(15)+++$ & $\mathrm{R}(12)+++$ & $\mathrm{R}(12)+++$ & $(20)++$ & $\mathrm{R}(10)+++$ & $\mathrm{R}(15)+++$ & $\mathrm{R}(10)+++$ \\
\hline SXT25 & $\mathrm{R}$ & $\mathrm{R}$ & $\mathrm{R}$ & $\mathrm{R}(12)+++$ & $\mathrm{R}$ & $\mathrm{R}$ & $\mathrm{R}$ \\
\hline
\end{tabular}

Degree of susceptibility: $+=$ susceptible/sensitive $(>21 \mathrm{~mm}),++=$ intermediate $(16$ to $20 \mathrm{~mm})$, and $+++=$ resistant $(\leq 15 \mathrm{~mm})$. R = resistant; AMP10, ampicillin; CAZ30, ceftazidime; CRX30, cefuroxime; CN10, gentamycin; CPR5, ciprofloxacin; OFL5, ofloxacin; AUG30, augmentin; NIT300, nitrofurantoin; E15, erythromycin; DA2, clindamycin; NA30, nalidixic acid; C30, chloramphenicol; SXT25, sulfamethoxazole/trimethoprim.
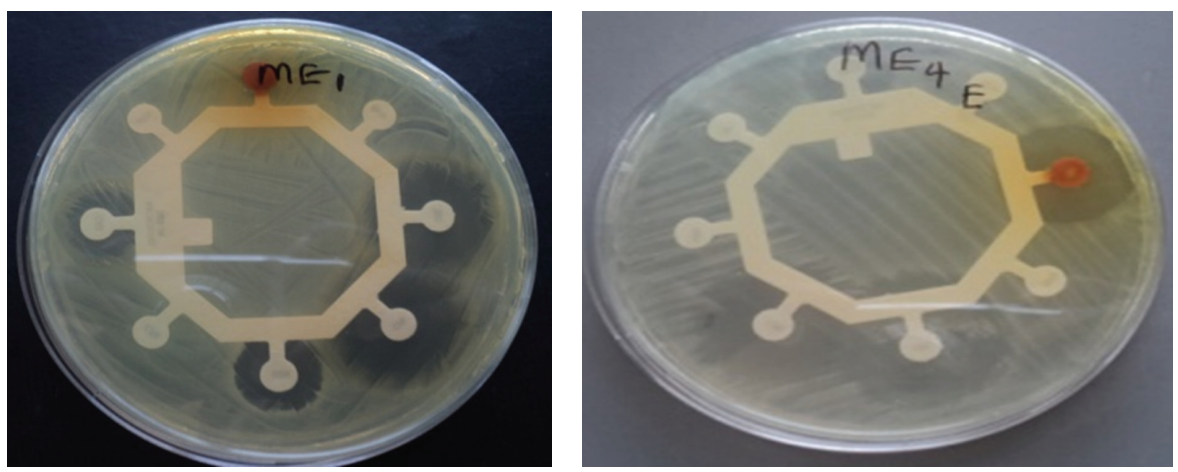

FIGURE 1: Susceptibility pattern of bacterial isolates.

TABLE 6: Probit response of Oreochromis niloticus to acutely toxic concentrations of the pharmaceutical wastewater.

\begin{tabular}{lccccc}
\hline $\mathrm{LC}_{5}(\mathrm{~mL} / \mathrm{L})$ & $\mathrm{LC}_{50}(\mathrm{~mL} / \mathrm{L})$ & $\mathrm{LC}_{95}(\mathrm{~mL} / \mathrm{L})$ & $\mathrm{SE}$ & DF & Probit-line equation \\
\hline $15.14(0.02-29.59)$ & $51.20(19.14-90.24)$ & $173.21(96.19-52485.55)$ & 1.32 & 2 & $Y=2.33-2.28 x$
\end{tabular}

$\mathrm{LC}_{5}$ : lethal concentration that will bring $5 \%$ mortality of the exposed population.

$\mathrm{LC}_{50}$ : median lethal concentration that will bring about $50 \%$ mortality to the exposed population.

$\mathrm{LC}_{95}$ : lethal concentration that will bring about $95 \%$ mortality of the exposed population. 


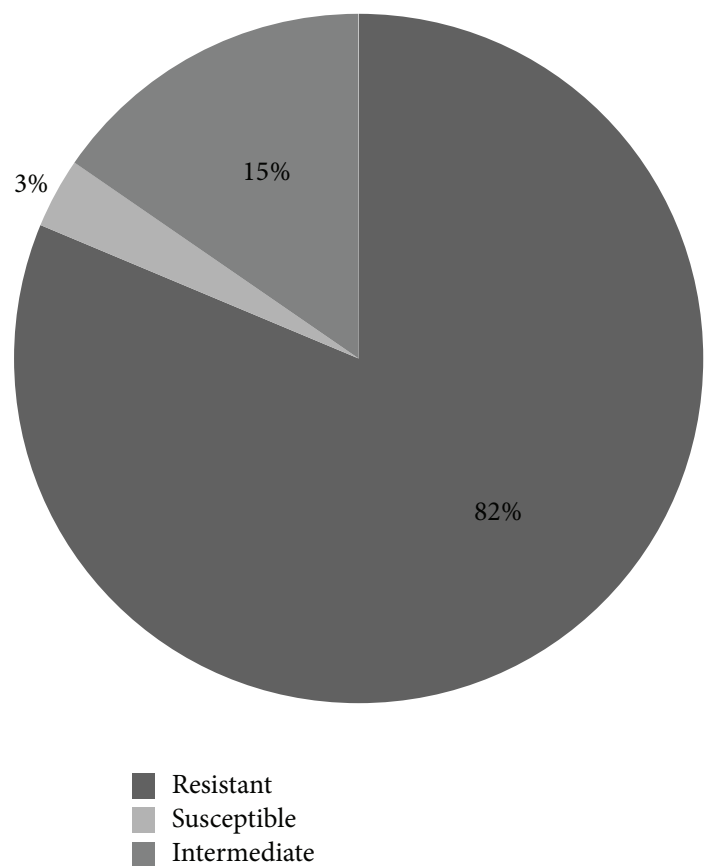

FIGURE 2: Percentage susceptibility of the bacterial isolates.

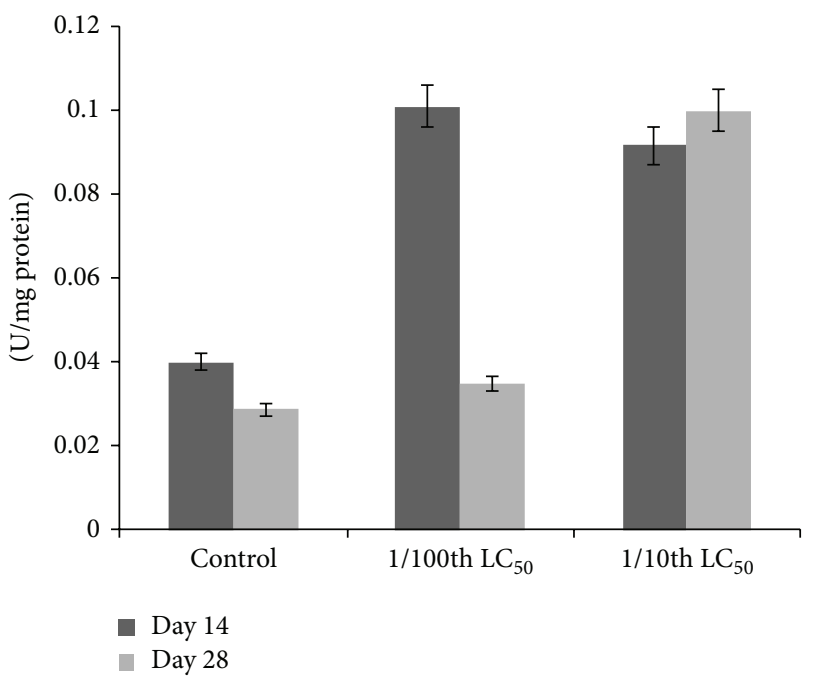

FIGURE 3: Malondialdehyde (MDA) levels in the liver of Oreochromis niloticus.

the least was recorded in those exposed to $1 / 100$ th $96 \mathrm{hrs} \mathrm{LC}_{50}$ $(P>0.05)$ (Figure 6).

3.2.10. Glutathione-S-Transferase. Much as with SOD, the GST enzyme activities were the least in the control group at day 14 and highest in those exposed to 1/100th 96 hrs $\mathrm{LC}_{50}$ concentration (Figure 7). By the 28th day of the study, the reverse was the case as control fingerlings had the highest GST activity $(P<0.05)$ followed by those exposed to $1 / 100$ th LC $_{50}$ concentrations. In this case, as with SOD, those exposed to 1/10th $96 \mathrm{hrs} \mathrm{LC}$ L $_{50}$ concentration of the wastewater recorded the least levels of GST at day 28 (Figure 7).

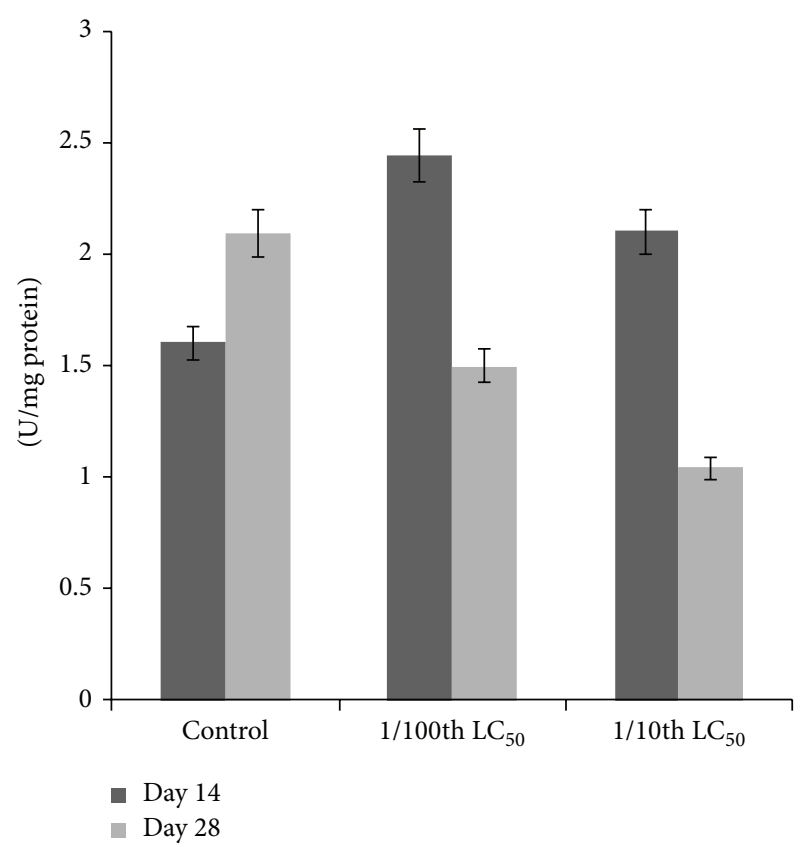

FIgURE 4: Superoxide dismutase (SOD) activities in the of Oreochromis niloticus.

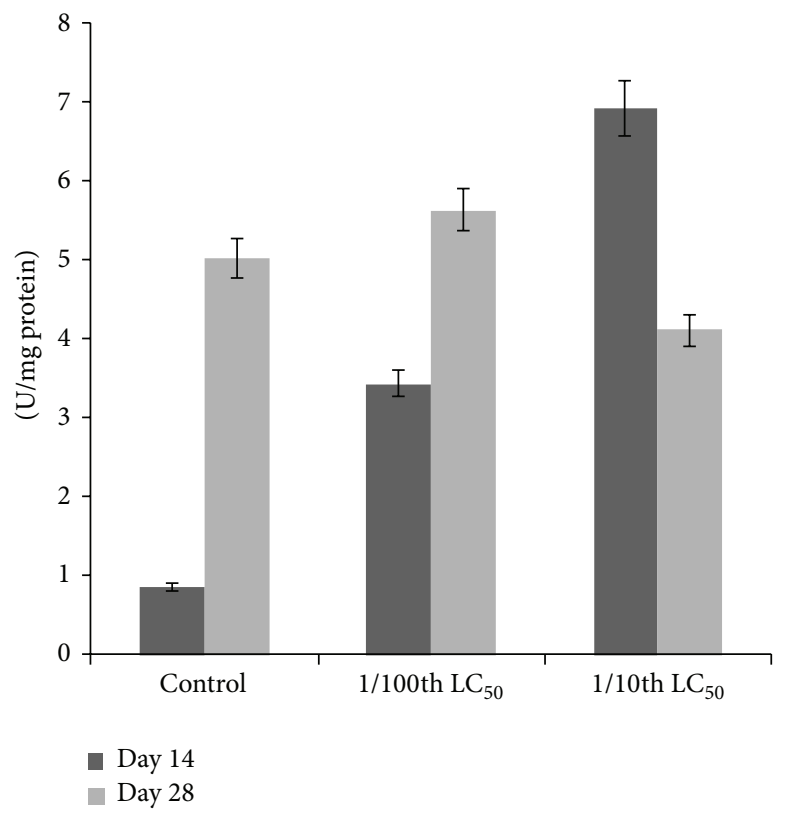

FIgURE 5: Catalase (CAT) activities in the liver of Oreochromis niloticus.

\section{Discussion}

In this preliminary study, we have successfully established that the bacterial isolates from the pharmaceutical wastewater investigated revealed multidrug resistant strains probably as a result of selective pressure from drug polluted waste wastewater and this is of public health concern. There is an indication of enzyme and antibiotic production of industrial application from some of the bacterial isolates. Thus there is 


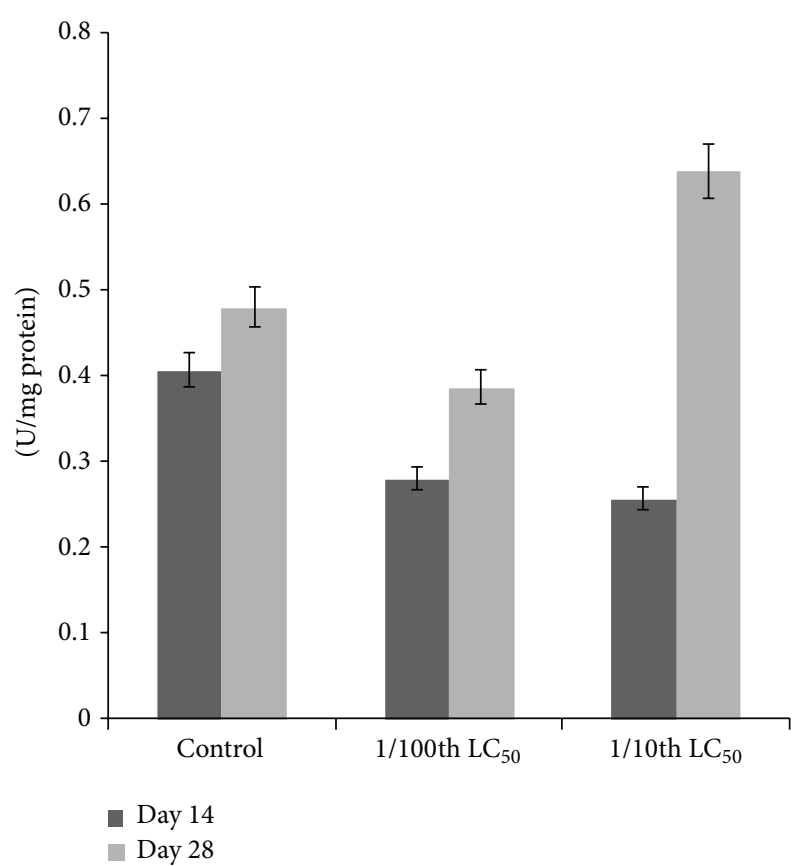

FIGURE 6: Reduced glutathione (GSH) activities (GST) in the liver of Oreochromis niloticus.

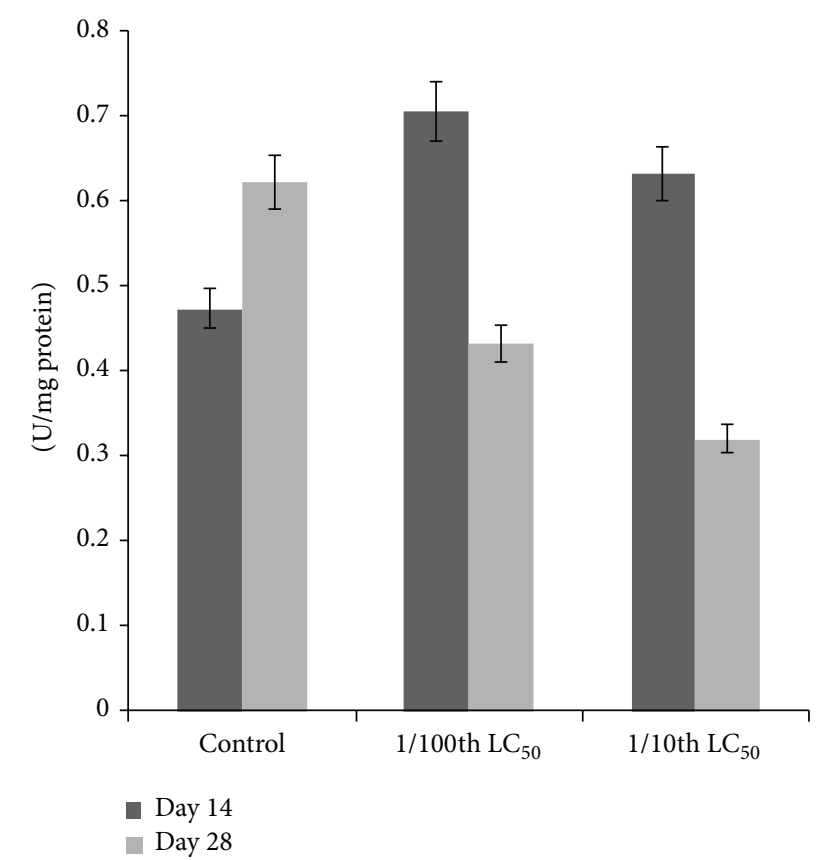

FIGURE 7: Glutathione-S-transferases activities in the liver of Oreochromis niloticus.

a need to exploit this opportunity to evaluate them for safety and toxicity to humans, animals, and the environment.

The findings from this study also showed that these bacterial isolates might be a potential source of antibacterial agent used to treat disease caused by Staphylococcus xylosus. The antibacterial substance produced by these isolates (ME2, $\mathrm{ME3}$, and ME7) might be utilized if further work is done to study the possibilities of them being potential therapeutic agents for applications in the pharmaceutical industries.

Further studies will be done to identify the species of all the isolates, and the most widely used method for identification is genetic techniques such as the 16S rRNA gene analysis for phylogenetic study [22].

Nonetheless, the toxicity of the wastewater to fingerlings of the tilapia, O. niloticus, implies that there is a need for proper treatment measures prior to discharge in order to protect sensitive aquatic wild life species. In the Lagos lagoon, for instance, effluent discharge is typically done in the coastal areas where the early life stages of fishes often thrive [8]. Given the current view that fish species in this lagoon are dwindling [8], the challenge of mitigation of effluent discharge becomes daunting.

When fishes are exposed to sublethal concentration of toxicants, depending on the respective constituents and mechanism of action, a variety of physiological and biochemical responses may be elicited in order to maintain the innate homeostatic balance. Typical first line of responses in fishes may include biochemical responses such as changes in the activities antioxidative stress enzymes like SOD, catalase and GST as well as reduction of glutathione in the cells. Given the fact that effluents are an admixture of diverse chemical constituents, it is not unlikely that some of its components may contain reactive oxygen species (ROS) which are precursors of oxidative damage to cell. ROS such as peroxides, superoxides, and singlet oxygen combine with the polyunsaturated fatty acids and their esters in cell membranes, damaging and dislodging their components, resulting in lipid peroxidation. The resulting lipid hydroperoxide decomposes into several components such as lipid alkyl radicals, aldehydes, alkanes, epoxides, and alcohols [23]. The aldehyde, malondialdehyde (MDA), is a principal lipid peroxidation product employed in assessing oxidative damage to cell membranes [24]. There was evidence of peroxidative damage to the cells of the tilapia as indicated by higher levels of MDA in those exposed to both sublethal concentrations of the effluents. One of the microbial isolates indicated high phospholipase activity which could have accounted for the phospholipid peroxidation damage reported in this study. The dynamic nature of damage and repair in cells is exemplified in the variation of the MDA levels over the period of exposure.

Free superoxides upon entrance into cells are faced with the degrading action of superoxide dismutase which catalytically breaks them down into hydrogen peroxide and water [9]. The inhibition of the SOD activities in the fingerlings between the 14th and 28th days of exposure observed in this study is indicative of early signs of oxidative stress. Catalase works in conjunction with SOD in further breaking down the hydrogen peroxide by products of dismutase activity [9]. Although the catalase activities observed in the fingerlings do not show an overall trend, catalase inhibition in those exposed to higher concentrations $\left(1 / 10\right.$ th $\left.\mathrm{LC}_{50}\right)$ also points to some level of stress.

The increasing levels of reduced glutathione (GSH) observed across all fingerlings in the study are an indication of active uptake of free anions by the glutathione components of the cells in order to minimize oxidative damage potentials 
of the peroxides. Among the exposed groups, there was also evidence of inhibition of GST activities by the 28th day of the sublethal assays, relative to the control, where an increase was observed. Leaver and George [25] reported significant inhibition of GST activities in catfishes exposed to crude oils, benzene, toluene, and xylene. GST naturally catalyzes the conjugation of GSH with oxidative products resulting in the oxidative degradation of DNA [25]. Thus increased generation of products of oxidative damage and concomitant increase in conjugation needs would result in increased utilization of GST. This however was not the case because the inhibition was recorded and may be associated with the overwhelming effect of the oxidative stress, which is characterized by inhibition of the activities of enzymes involved in antioxidative stress mechanisms.

The general state of wastewater quality implies that there is need for proper treatment before discharge into the aquatic ecosystem because many of the parameters examined were higher than the FEPA standards for natural water bodies. Although dilution factors in natural water bodies would ease out their eventual concentrations, the high concentrations of manganese for instance are of concern given its link with loss of neuromotor function [26].

\section{Conclusion}

In this study, we have been able to relate the ability of microorganisms to survive and develop certain antibiotic resistance capabilities due to selective pressure in the drug polluted waste water [27]. The acute toxicity of the wastewater on sensitive fingerlings of $O$. niloticus raises salient effluent quality concerns. The biochemical responses in the fishes are indicative of the onset of oxidative stress which has the ability of impairing other life functions and the health of the fishes.

Antibiotic resistance acquisition due to selective pressure is of public health concerns as resistance genes can be disseminated in nature and transferred to pathogenic counterparts of bacterial species by genetic mobile elements [28]. Thus there is need to effectively treat drug waste water before discharge into the environment.

Overall, findings from the microbiological assays and consistent trend in most oxidative stress markers from the biochemical assays imply that a combination of both assays could be routinely used in pharmaceutical effluent quality monitoring before discharges into natural water bodies.

\section{Conflict of Interests}

The authors declare that there is no conflict of interests regarding the publication of this paper.

\section{References}

[1] J. D. Salierno and A. S. Kane, " $17 \alpha$-ethinylestradiol alters reproductive behaviors, circulating hormones, and sexual morphology in male fathead minnows (Pimephales promelas)," Environmental Toxicology and Chemistry, vol. 28, no. 5, pp. 953961, 2009.
[2] M. A. Idris, B. G. Kolo, S. T. Garba, and M. A. Ismail, "Physicochemical analysis of pharmaceutical effluent and surface water of River Gorax in Minna, Niger State, Nigeria," Bulletin of Environment, Pharmacology and Life Sciences, vol. 2, no. 3, pp. 45-49, 2013.

[3] A. Lateef, "The microbiology of a pharmaceutical effluent and its public health implications," World Journal of Microbiology and Biotechnology, vol. 20, no. 2, pp. 167-171, 2004.

[4] S. T. Sankpal and P. V. Naikwade, "Heavy metal concentration in effluent discharge of pharmaceutical industries," Science Research Reporter, vol. 2, no. 1, pp. 88-90, 2012.

[5] R. J. Golden, K. L. Noller, L. Titus-Ernstoff et al., "Environmental endocrine modulators and human health: an assessment of the biological evidence," Critical Reviews in Toxicology, vol. 28, no. 2, pp. 109-227, 1998.

[6] T. E. Denton, W. M. Howell, J. J. Allison, J. McCollum, and B. Marks, "Masculinization of female mosquitofish by exposure to plant sterols and Mycobacterium smegmatis," Bulletin of Environmental Contamination and Toxicology, vol. 35, no. 1, pp. 627-632, 1985.

[7] Y.-P. Xie, Z.-Q. Fang, L.-P. Hou, and G.-G. Ying, "Altered development and reproduction in western mosquitofish (Gambusia affinis) found in the Hanxi River, southern China," Environmental Toxicology and Chemistry, vol. 29, no. 11, pp. 2607-2615, 2010.

[8] N. H. Amaeze, R. I. Egonmwan, A. F. Jolaosho, and A. A. Otitoloju, "Coastal environmental pollution and fish species diversity in Lagos Lagoon, Nigeria," International Journal of Environmental Protection, vol. 2, no. 11, pp. 8-16, 2012.

[9] J. Timbrell, Principles of Biochemical Toxicology, Taylor \& Francis, 3rd edition, 2000.

[10] APHA-AWWA-WEF, Standard Methods for the Examination of Water and Wastewater, 21st edition, 2005.

[11] ASTM, "Method D2887-93 test method for boiling range distribution of petroleum fractions by gas chromatography," in Annual Book of ASTM Standards, vol. 5, p. 27, American Society for Testing and Materials, Philadelphia, Pa, USA, 1997.

[12] S. C. U. Nwachukwu and T. V. I. Apata, Principles of Quantitative Microbiology, University of Lagos Press, Lagos, Nigeria, 1st edition, 2003.

[13] P. K. Talaro, Foundations in Microbiology, Pearson Benjamin Cummings, San Francisco, Calif, USA, 2009.

[14] D. T. John, H. J. James, P. R. Murray et al., Manual of Clinical Microbiology, American Society for Microbiology, Washington, DC, USA, 7th edition, 2009.

[15] S. A. Liasi, T. I. Azmi, M. D. Hassan, M. Shuhaimi, M. Rosfarizan, and A. B. Ariff, "Antimicrobial activity and antibiotic sensitivity of three isolates of lactic acid bacteria from fermented fish product, Bud," Malaysian Journal of Microbiology, vol. 5, pp. 33-37, 2009.

[16] A. A. Otitoloju and K. N. Don-Pedro, "Establishment of the toxicity ranking order of heavy metals and sensitivity scale of benthic animals inhabiting the Lagos lagoon," West African Journal of Ecology, vol. 3, pp. 31-41, 2002.

[17] K. Yagi, "Simple procedure for specific assay of lipid hydroperoxides in serum or plasma," Methods in Molecular Biology, vol. 108, pp. 107-110, 1998.

[18] M. Sun and S. Zigman, "An improved spectrophotometric assay for superoxide dismutase based on epinephrine autoxidationn," Analytical Biochemistry, vol. 90, no. 1, pp. 81-89, 1978. 
[19] A. Aksenses and L. Najaa, "Determination of catalase activity in fish," Comparative Biochemistry and Physiology, vol. 69, pp. 893-896, 1981.

[20] J. Sedlak and R. H. Lindsay, "Estimation of total, proteinbound, and nonprotein sulfhydryl groups in tissue with Ellman's reagent," Analytical Biochemistry, vol. 25, pp. 192-205, 1968.

[21] W. H. Habig, M. J. Pabst, and W. B. Jakoby, "Glutathione $S$ transferases. The first enzymatic step in mercapturic acid formation," The Journal of Biological Chemistry, vol. 249, no. 22, pp. 7130-7139, 1974.

[22] F. Rasheed, A. Khan, and S. U. Kazmi, "Bacteriological analysis, antimicrobial susceptibility and detection of $16 \mathrm{~S}$ rRNA gene of Helicobacter pylori by PCR in drinking water samples of earthquake affected areas and other parts of Pakistan," Malaysian Journal of Microbiology, vol. 5, pp. 123-127, 2009.

[23] A. Valavanidis, T. Vlahogianni, M. Dassenakis, and M. Scoullos, "Molecular biomarkers of oxidative stress in aquatic organisms in relation to toxic environmental pollutants," Ecotoxicology and Environmental Safety, vol. 64, no. 2, pp. 178-189, 2006.

[24] A. Otitoloju and O. Olagoke, "Lipid peroxidation and antioxidant defense enzymes in Clarias gariepinus as useful biomarkers for monitoring exposure to polycyclic aromatic hydrocarbons," Environmental Monitoring and Assessment, vol. 182, no. 1-4, pp. 205-213, 2011.

[25] M. J. Leaver and S. G. George, "A piscine glutathione Stransferase which efficiently conjugates the end-products of lipid peroxidation," Marine Environmental Research, vol. 46, no. 1-5, pp. 71-74, 1998.

[26] D. Mergler, M. Baldwin, S. Belanger et al., "Manganese neurotoxicity, a continuum of dysfunction: results from a community based study," NeuroToxicology, vol. 20, no. 2-3, pp. 327-342, 1999.

[27] H. K. Allen, J. Donato, H. H. Wang, K. A. Cloud-Hansen, J. Davies, and J. Handelsman, "Call of the wild: Antibiotic resistance genes in natural environments," Nature Reviews Microbiology, vol. 8, no. 4, pp. 251-259, 2010.

[28] E. M. H. Wellington, A. B. A. Boxall, P. Cross et al., "The role of the natural environment in the emergence of antibiotic resistance in Gram-negative bacteria," The Lancet Infectious Diseases Review, vol. 13, no. 2, pp. 155-165, 2013. 

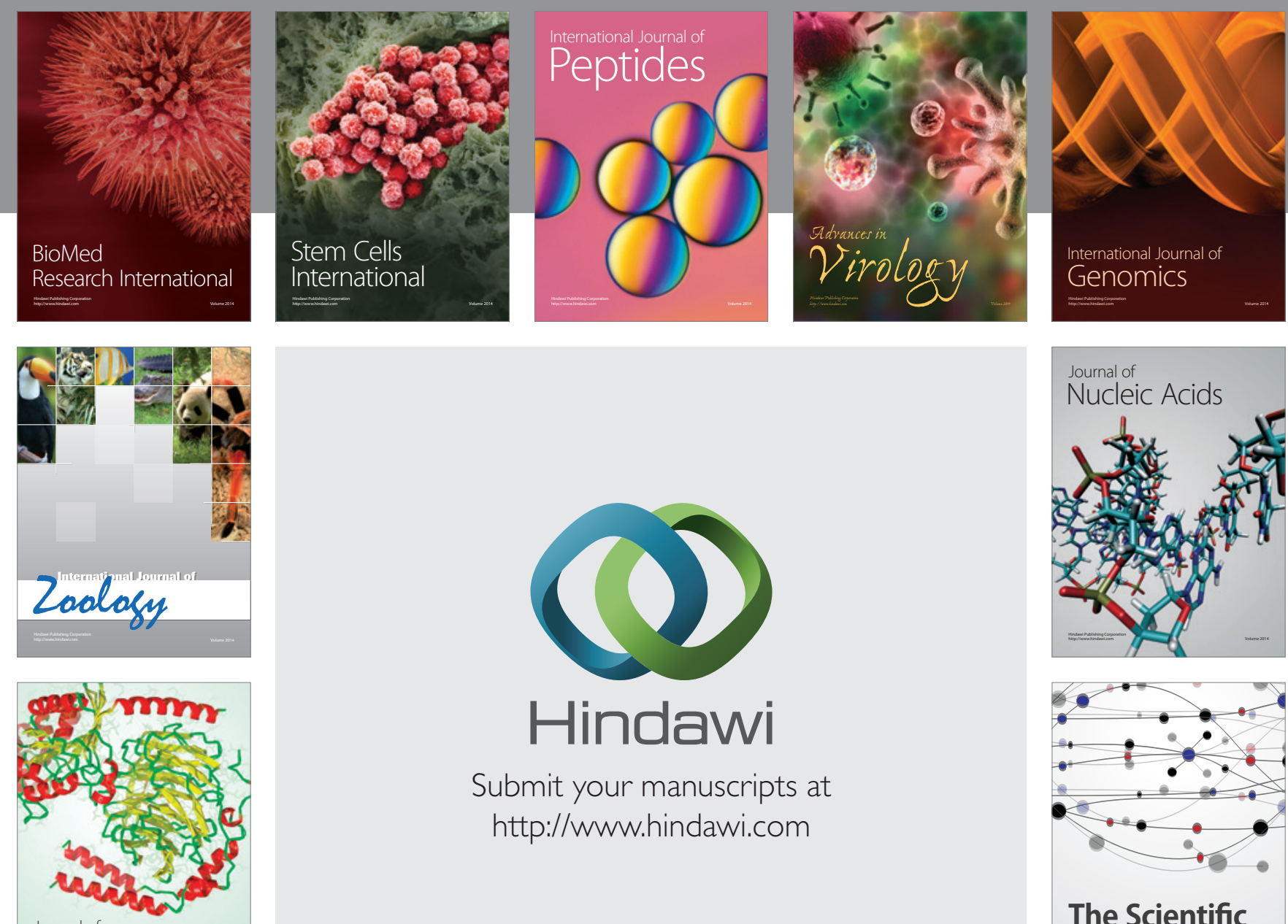

Submit your manuscripts at

http://www.hindawi.com

Journal of
Signal Transduction
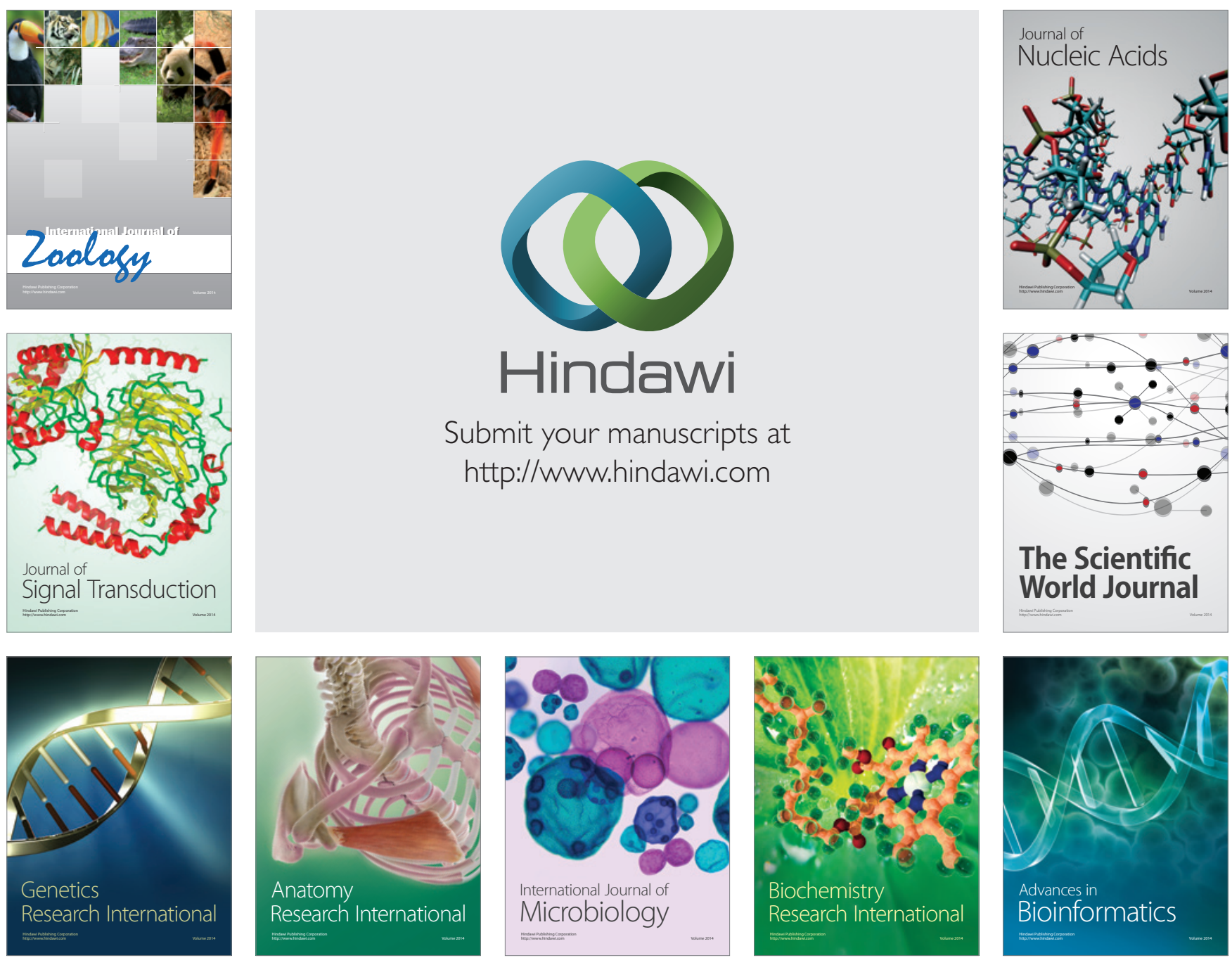

The Scientific World Journal
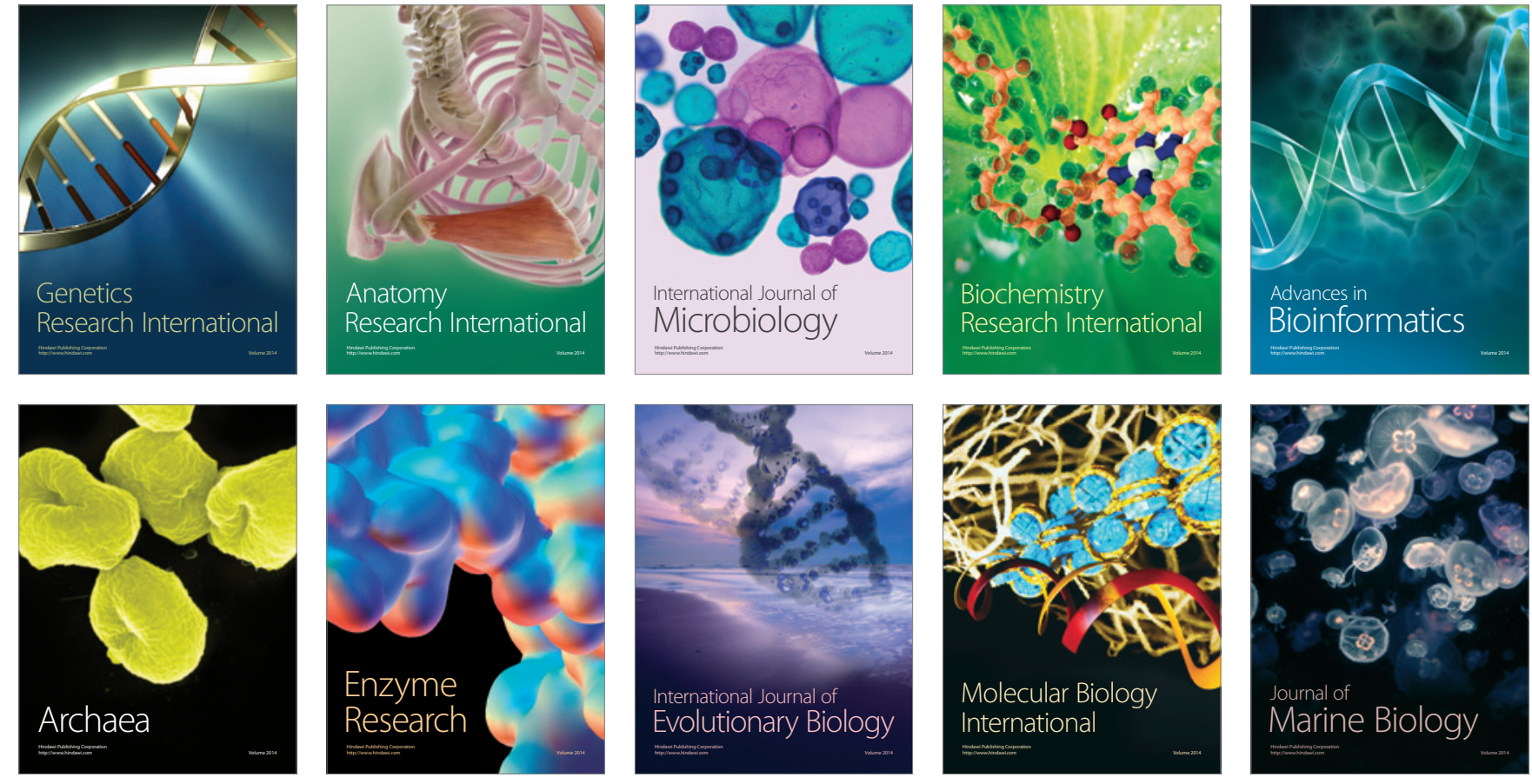